\title{
Implementing Pre-Reading Strategies to Improve Struggling ESL Learners' Interest and Comprehension in English Reading Lessons
}

\author{
T. Gewa Thuraisingam, Santhi Gopal, Nisha Sasidharan, Zahra Naimie, Adelina Asmawi \\ Faculty of Education, University of Malaya, Kuala Lumpur, Malaysia
}

Email address:

rajugewa@yahoo.com (T. G. Thuraisingam),santhi.gopaal@gmail.com (S. Gopal), Isha_gal79@yahoo.com (N. Sasidharan), zahra@um.edu.my (Z. Naimie), adelina@um.edu.my (A. Asmawi)

\section{To cite this article:}

T. Gewa Thuraisingam, Santhi Gopal, Nisha Sasidharan, Zahra Naimie, Adelina Asmawi. Implementing Pre-Reading Strategies to Improve Struggling ESL Learners' Interest and Comprehension in English Reading Lessons. International Journal of Education, Culture and Society. Vol. 2, No. 3, 2017, pp. 94-100. doi: 10.11648/j.ijecs.20170203.13

Received: March 4, 2017; Accepted: March 27, 2017; Published: May 9, 2017

\begin{abstract}
This paper presents the implementation of pre-reading strategies to facilitate reading skills and increase interest in reading lessons among struggling ESL primary school pupils using the Fuzzy Delphi Method (FDM) and Fuzzy Analytic Hierarchy Process (FAHP) which is a multiple-attribute decision process that is normally made by a review committee with experts from academia. It also aims at providing a systematic approach to selecting appropriate pre-reading strategies to improve pupils' interest and comprehension in English reading lessons. In this study, six English Language teachers from Kuala Lumpur participated as experts to answer a questionnaire in the Fuzzy Delphi method to determine pre-reading strategies that facilitate reading among struggling Year Four pupils. A total of 250 Year Four pupils participated in a comprehension pretest from which thirty-five struggling Year Four pupils were selected. Through the Fuzzy Delphi Method (FDM) and the Fuzzy Analytic Hierarchy Process (FAHP), three key pre-reading strategies were selected and sequenced according to their degree of importance as selected by the experts. The percentage of consensus achieved was $85 \%$ and the fuzzy hierarchy for pre-reading strategies was determined and ranked according to its importance namely activating prior knowledge, teaching explicit vocabulary, and conducting role-play. These strategies were implemented by the expert teachers during two English reading Research Cycles after which a post-test was administered. The post-test and checklists of observation on expert teachers indicated that the chosen pre-reading strategies had a significant effect in increasing pupils' interest and comprehension in reading.
\end{abstract}

Keywords: Pre Reading Strategies, Enhance, Reading Comprehension, Struggling Pupils

\section{Introduction}

Reading is a very important skill that primary school pupils need to master. Reading involves connecting new text to that which is already understood called schema or prior knowledge (Pearson \& Cervetti [1]). When teaching reading in the English Language classroom in Malaysia, teachers encounter struggling readers who have difficulties comprehending the passage. Therefore they need to use strategies to get pupils to activate existing knowledge, thereby creating a mental framework to which new text, terms, ideas can be attached. Through the Fuzzy Delphi Method (FDM) and the Fuzzy Analytical Hierarchy Process (FAHP), key pre-reading strategies were selected and sequenced. Finally, the key pre-reading strategies were carefully applied to help struggling pupils to comprehend what they read and create interest in the English reading lesson. It is hoped that these strategies would help struggling readers to become fluent readers.

\section{Comprehension Difficulties Faced by Struggling Readers}

Teaching reading comprehension to struggling readers requires teachers to apply multiple pre-reading strategies to enhance these pupils' reading comprehension. Struggling readers need to be taught to improve comprehension and 
interest in their reading when these do not make sense to them (Scanlon, Anderson \& Sweeney [2]). The goals of the pre-reading stage are to activate the students' knowledge of the subject, to provide any language preparation that might be needed for coping with a passage and, finally to motivate the learners to want to read the text (Azizifar, Roshani, Gowhary \& Jamalinesari [3]). Bell [4] stated that pre-reading activities are 'enabling activities' because they provide readers with necessary background to organize activity and to comprehend the material. In addition, it sets the reader to elicit knowledge and focus attention. This is what struggling students need in reading lessons.

Hence this research aimed at investigating the effectiveness of teaching pre-reading strategies among struggling pupils to enhance reading comprehension thus improving their interest in reading lessons. In order to analyze the experts' opinion about the most effective pre-reading strategies, the Fuzzy Delphi Method (FDM) and the Fuzzy Analytic Hierarchy Process (FAHP) were used to increase accuracy of the findings.

\section{Fuzzy Delphi Method and Fuzzy Analytic Hierarchy Process}

The traditional Delphi Method, developed by Dalkey \& Helmer [5], has been widely used to obtain a consistent flow of answers through the results of questionnaires (Bouzon, Govindan, Rodriguez, \& Campos [6]). Delphi is an expert opinion survey method with three features: anonymous response, iteration and controlled feedback, and finally statistical group response. However, some weaknesses have been exposed; it needs repetitive surveys to allow forecasting values to converge which requires much more time and cost (Skinner, Nelson, Chin \& Land [7]). Furthermore, in many real situations, experts' judgments cannot be properly reflected in quantitative terms. Some ambiguity will result because of differences in the meanings and interpretations of the expert's opinions. Since people use linguistic terms, such as 'good' or 'very good' to reflect their preferences, the concept of combining fuzzy set theory and Delphi was proposed by Murray, Pipino \& Gigsh [8], and named the Fuzzy Delphi Method (FDM).

When it comes to multiple criteria decision-making problem the Fuzzy Analytic Hierarchy Process (FAHP) is one of the most popular (Calabrese, Costa, Levialdi, \& Menichini [9]). In this study, experts need to select pre-reading strategies laid out in the questionnaire and rank them according to their degree of importance to be used in the English reading classroom. Therefore, both the Fuzzy Delphi Method (FDM) and Fuzzy Analytic Hierarchy Process (FAHP) were used since these approaches could resemble human reasoning in the use of prereading strategies to enhance reading comprehension and interest among pupils. Consequently, to make this study more sensible and gain a more representative description of the decision-making process, this study would apply the FAHP to investigate which evaluation criterion is the most important in selecting pre-reading strategies.

\section{Purpose of Study}

The purpose of this study was to investigate the effectiveness of teaching pre-reading strategies to increase pupils' interest in English reading lessons and enhance reading comprehension among struggling pupils. Specifically, the following questions were addressed in this study:

i. To what extent can the use of pre-reading strategies increase pupils' interest towards English reading lessons?

ii. To what extent do pre-reading strategies enhance reading comprehension among struggling pupils?

\section{Pre-reading Strategies}

\subsection{Activating Background Knowledge/Schema}

The pre-reading plan begins with the teacher introducing a key word, concept or picture to stimulate a discussion. By having the students say anything that initially comes to mind and having that information recorded on the whiteboard, participants are able to see the associations. By asking the students questions such as, "What made you think of...?" they become aware of their network of associations (Alqami [10]). These are examples of activating the schema. Jingwei [11] states that struggling and at-risk readers lack schema to help them comprehend the reading text. Jingwei also adds that teachers need to increase schema in the classroom as much as possible. This is because teaching background information about a topic can improve students' comprehension of text (Gajria \& Jitendra [12]).

\subsection{Vocabulary Pre Teaching}

New vocabulary should be taught prior to reading as the reader will spend too much time figuring out the new words, and will be unable to comprehend the entire reading passage (Pellicer-Sanchez [13]). Quinn, Wagner, Petscher \& Lopez [14] stated that words are organized into an intricate, interlocking system, therefore they cannot be learned in isolation without considering their related context. McKeown \& Curtis [15] have found strong correlations between vocabulary knowledge and reading comprehension. There has been increased interest by researchers in examining the effects of vocabulary instruction on passage comprehension (Garcia \& Cain [16]).

\subsection{Role Play in Reading Comprehension}

Role playing has a communicative aspect that helps students acquire new knowledge and engage through nonthreatening experiences (Yusuf [17]). Gilje [18] describes the benefits of using role playing and drama as pedagogical tools to help students learn new vocabulary while building their confidence and interest in using the English language. Readers Theatre (Myrset [19]) is another way role play can be used in the classroom for students to practice oral interpretation, expression, vocabulary development, and 
overall reading comprehension, as well as improve fluency. Capellini, Pinto \& Cunha [20] states that role play in teaching and learning genre could improve students' comprehension. Vaish also [21] found improved self-concept after using role play to improve reading comprehension. Moreover, role play also provided more insight into the different ways visualization can be used to encourage readers to build non-linguistic representations of text.

\section{Pupils' Interest in Reading}

Through reading, one has access to a wide range of knowledge found in various reading materials such as academic books, magazines, newspapers and journals (US Department of Education [22]. However, struggling pupils lack interest in reading because they fail to comprehend what they read; thus they give up on this very important skill altogether. Those who do not know how to read or do not like to read will likely be stagnant in their understanding as they fail to benefit from the opportunity to gain access to the wide range of knowledge. Besides, when readers read to get information, they indirectly improve their reading skills. This is supported by Sparks, Patton and Murdoch [23] who stated that by reading, one learns to read and becomes better at reading. Hence, people who read extensively can become good readers as they are exposed to new vocabulary. As a result, they will like reading and become successful readers.

The early experience that English as a second language (ESL) pupils encounter when reading second language materials could determine their interest and attitudes toward reading (Young, Mohr \& Rasinki [24]). They also stated that pupils will employ their reading interest and attitude that they have gained towards reading in a second language as they xadvance to the development stages of reading.

\section{Methodology}

This study was conducted in six schools in the urban city of Kuala Lumpur and the subjects were Year Four pupils. A total of
250 Year Four pupils from six classes from each of these schools were selected. Six Year Four English Language teachers or experts were selected from these six schools to complete a questionnaire. The questionnaires were analyzed and consensus from the experts was achieved to determine the pre-reading strategies that would be used as intervention methods. The consensus was then translated into a hierarchy framework of pre-reading strategies (Figure 2) to help implement these strategies according to their degree of importance in the English reading classroom. At the same time, since the fuzziness of human thought can be further expressed, the Fuzzy Delphi Method (FDM) and Fuzzy Analytic Hierarchy Process (FAHP) were employed to increase the accuracy of the findings (Eisavi, Homayouni \& Karami [25]).

For the pupils, instruments such pre and post-tests were used. The expert teachers then administered the pre-test to Year 4 pupils that they taught and chose struggling readers who did not perform well in the test. Based on the scores of the pre-test completed by two-hundred and fifty Year Four pupils, thirty-five struggling pupils from the six schools in Kuala Lumpur were identified and chosen to participate in this research. The teachers applied the pre-reading strategies which were specifically selected through the Fuzzy Delphi Method (FDM) and Fuzzy Analytic Hierarchy Process (FAHP) and used them in two Research Cycles of reading lessons based on the same text.

Teachers or experts involved were interviewed and their reflections were transcribed. Moreover, observation checklists were used by the expert teachers to observe pupils' comprehension and interest in reading. These observations were carried out during teaching and carefully recorded by the expert teachers.

The expert teachers were given specific guidelines to use a passage from the Year 4 English Textbook entitled "Computer Games" by Hyacinth Gaudart. This comprehension passage from the Year Four English textbook was chosen as it was suitable for the level of pupils' English language proficiency. Moreover the English textbook is part of the English Language curriculum for Year Four.

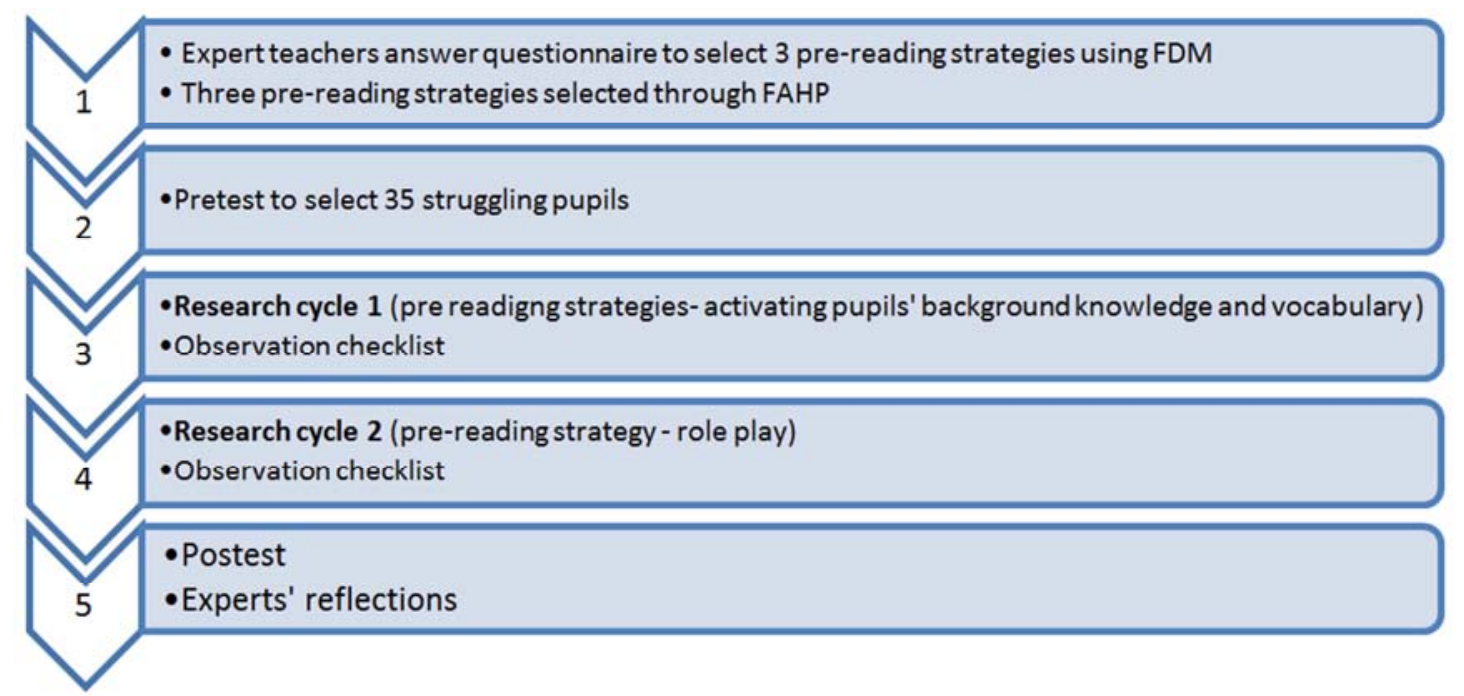

Figure 1. Shows the Methodology of the Study. 


\subsection{Research Cycle One}

Teacher planned to carry out the intervention strategy to activate prior knowledge and teaching vocabulary. These two pre-reading strategies were carried out together because activation of prior knowledge enhances vocabulary acquisition.

Steps:

Step 1 - Teacher used pre-reading instructions to activate pupils' background knowledge by showing a picture of a computer. Teacher asked questions regarding the picture and further probed them regarding games that they play on the computer. Then teacher showed a cartoon clip 'Boboboi' where the main character enters into the computer and becomes a player of the computer games.

Step 2 - Pupils looked at the passage and underlined words they did not understand. Teacher showed pictures and gestures while relating to the pupils' prior knowledge. Teacher handed vocabulary test 1 worksheet where pupils match pictures with words.

Step 3 - Teacher modeled reading the passage and demonstrated key phrases using actions to facilitate pupils' understanding.

Step 4 - Pupils read the passage in groups and individually. Teacher asked oral questions to check understanding.

Step 5 - Pupils completed vocabulary test 2 worksheet which is a cloze passage of the passage they just read with blank spaces for pupils to fill in by choosing the correct answers.

\subsection{Research Cycle Two}

In this research cycle, the teacher planned to teach the intervention using role play as this was a narrative passage and literature review had shown that role play facilitated pupils' comprehension.

Steps:

Step 1 - Teacher read the passage to pupils. Teacher asked pupils to name the characters in the story. Teacher guided pupils to find the characters and the setting of the story. Teacher wrote the answers on the board. Teacher assigned roles to each pupil.

Step 2 - Teacher asked two pupils to memorize the dialogue as shown in the passage.

Pupil 2- (the old woman) "What do you want, young man?"

Pupil 1- (the player) "May I rest here?"

Pupil 2- (the old woman) "Sure" (and laughed aloud)

Four pupils played the roles of:

i). first house

ii). second house with lots of jewels

iii). wind

iv). Ali who would say "You have won the game"

Step 3 - Teacher read the passage and pupils mimicked according to their roles.

Step 4 - After the role play, teacher asked questions to check pupils' understanding.

After the two cycles of reading lessons using these three pre-reading strategies (Figure 2), a post test was carried out to determine the pupils' level of comprehension. In addition, all expert teachers also made observations using a checklist to gauge pupils' comprehension level and interest in the ESL reading classrooms. Teachers were also interviewed and their reflections were transcribed.

\subsection{Consensus of Experts Through Fuzzy Delphi Method}

Based on the five point linguistic scale questionnaire containing 10 questions, the evaluation values of triangular fuzzy number of each alternate factor chosen by the experts were calculated. After that, the average and threshold values were calculated. The percentage of consensus achieved was $85 \%$, therefore subsequent rounds of questionnaire were not needed (Cheng \& Lin, 2002). After the defuzzication process was carried out, the fuzzy hierarchy framework for prereading strategies was determined according to its ranking as shown in Figure 2.

\section{Pre-Reading Strategies to Enhance Reading Comprehension Among Struggling Pupils}

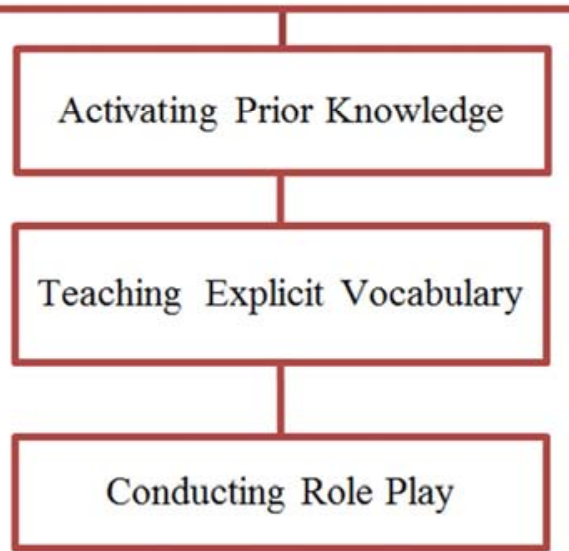

Figure 2. Shows the Hierarchy Framework of pre-reading strategies using FAHP. 
From Figure 2 above, three pre-reading strategies used as intervention methods were activating prior knowledge, teaching explicit vocabulary and conducting role-play.

\section{Discussions}

\subsection{The Use of Pre-reading Strategies Increase Pupils' Interest Towards English Reading Lessons}

In the beginning of the research, teachers from six selected schools in the Kuala Lumpur were given questionnaires to find out about struggling readers in their respective schools. Most of the teachers gave their feedback about their pupils' inability to understand what they read.

However, after the intervention of pre-reading strategies such as vocabulary knowledge and, activating pupils' prior knowledge were carried out in Research Cycle 1, all the pupils were able to respond positively toward the English reading lesson.

The interview except of Mizan (pseudonym) a teacher at one of the selected schools on Research Cycle one is shown on Table 1.

Table 1. Findings from Observation of Research Cycle One.

Students showed a lot of interest in the lesson and gave numerous responses when I questioned them about computer games using the visuals. They were able to relate the computer games passage with the cartoon story 'Boboboi' which has a similar storyline to this passage. However, at the end they were not able to make inference as to who actually played the game in this story. They could not point out whether it was Ali or the writer of the passage. Therefore, another cycle of research was carried out in which role play was incorporated to help pupils understand the passage better.

Mizan (pseudonym), line 7, 16 August 2013

From the example as shown in Table 1, one of the teachers named Mizan (pseudonym) who participated in the interview mentioned that activating pupils' prior knowledge through the visual and the cartoon clip "Boboboi' in Research Cycle 1 helped pupils to make mental connections with the passage titled "Computer Games" by Hyacinth Gaudart.

Another finding to show that pre-reading strategies changed pupils' interest toward learning English can be seen from the observation result shown in Table 1 by the teacher researcher. After pupils' background knowledge had been activated, pupils were able to respond to the visual of the computer as reflected by an expert in Table 1. When pupils' schema is activated, they were able to connect to the new passage with ease. Further, when the teacher taught the vocabulary explicitly, the pupils were more confident even though they were struggling pupils.

The intervention using role-play as a pre-reading strategy in Research Cycle 2 was another element that contributed positively to pupils' interest towards the reading lesson. The observation of Leena (pseudonym), a teacher from one of the selected schools on research cycle two is shown in Table 2.
Table 2. Findings from Observation of Research Cycle Two.

During the role-play intervention, the students internalized the characters in the passage. The pupils were able to say their lines and mimic according to their turns. As the role-play was repeated, the pupils were more confident to say their lines and mimic with more accuracy. The pupils also switched roles and performed other roles with ease. When the teacher asked them who actually won the game, the pupils collectively answered "the writer". Based on this correct answer response, the teacher carried out the post test.

Leena (pseudonym), line 5, 24 August, 2013

From the observation by the teacher as shown in Table 2, Leena (pseudonym) observed that pupils showed more interest and slowly began to comprehend the passage. This was evident as they took part in the role-play because they were able to internalize the sequence of the narrative and act it out accurately.

These findings suggest that intervention of pre-reading strategies such as activating pupils' prior knowledge and role play increased pupils' interest in learning English. The response from the teachers' observations also showed that the pupils enjoyed the lesson especially the role-play which was an element of fun in the learning process.

\subsection{Pre-reading Strategies Enhance Reading Comprehension Among Struggling Pupils}

To answer the second research question on the extent of pupils' reading comprehension among struggling pupils was enhanced, the comparison of the pre and post-tests was made. The low scores obtained by each pupil in the pre-test as compared to the $80-95 \%$ scores of the posttest by all the pupils speak volumes. This clearly suggests that the intervention of pre-reading strategies using explicit vocabulary, activating pupils' schema during Research Cycle 1 and role play in Research Cycle 2 facilitated pupils' reading comprehension.

Although all the expert teachers from the six selected schools stated that the pupils could not fully comprehend the passage, the intervention activity of teaching explicit vocabulary conducted by the teachers did help them to understand meanings of words in context. Pupils from all five selected schools scored $100 \%$ for the second vocabulary activity which clearly proved that they could understand the meaning of words better than before.

Moreover, based on the result of the Research Cycle 1 shown on Table 1, the teacher observed that pupils could not make inference about who actually won the game. However, after the role-play was carried out during Research Cycle 2, pupils could answer the question correctly by working out the answer themselves (see Table 2). This shows that pre-reading strategies such as activating pupils' prior knowledge, teaching explicit vocabulary and role-play contributed positively toward helping pupils to understand and improve interest in reading comprehension. All these pointed to the effectiveness of prereading strategies in enhancing comprehension and interest in reading among struggling students. 


\section{Conclusion of Research Findings}

In conclusion, the expert teachers from the six selected schools voiced their satisfaction because all 35 pupils had shown marked improvements not only in their scores but in their overall interest in English Language reading. The interventions the teachers used for pre-reading activities were proven successful for struggling pupils to comprehend the passage "Computer Games" by Hyacinth Gaudart and were effective in overcoming problems faced by these struggling readers. By observing these significant improvements, all the teachers involved in this research would continue using these strategies in their reading classroom in the future.

The results of these findings, even though applied to this small sample or subjects, had a great impact by means of these interventions to help struggling pupils in reading comprehension and this can be applied to other pupils or classrooms. The rationale of the intervention is not only to improve the pupils' comprehension and interest in reading but also to enhance the teaching methods of the teachers involved in this research. In other words, the teachers learned something important through this research as they reflected on their teaching methods.

\section{Recommendations for Further Research}

It is suggested that English Language teachers carry out more intervention based activities to help pupils in their reading such as activating pupils' schema or prior knowledge, teaching explicit vocabulary and conducting role-play so that these interventions would help pupils respond by speaking their minds and getting more involved in the reading classroom. Teachers are also encouraged to experiment with other strategies to help struggling pupils become more competent readers. A bigger scale research may also be conducted to add depth and breadth to the research area.

\section{References}

[1] Pearson, P. D., \& Cervetti, G. N. (2015). Fifty years of reading comprehension theory and practice. Research-based practices for teaching Common Core literacy, 1-24.

[2] Scanlon, D. M., Anderson, K. L., \& Sweeney, J. M. (2016). Early intervention for reading difficulties: The interactive strategies approach. Guilford Publications.

[3] Azizifar, A., Roshani, S., Gowhary, H., \& Jamalinesari, A. (2015). The effect of pre-reading activities on the reading comprehension performance of ilami high school students. Procedia-Social and Behavioral Sciences, 192, 188-194.

[4] Bell, F. L. (2017). Comprehension aids, internet technologies, and the reading of authentic materials by adult second language learners. Dissertation Abstracts International, 66, 2517-18.

[5] Dalkey, N., \& Helmer, O. (1963). An experimental application of the Delphi method to the use of experts. Management Science, 9, 458-467.
[6] Bouzon, M., Govindan, K., Rodriguez, C. M. T., \& Campos, L. M. (2016). Identification and analysis of reverse logistics barriers using fuzzy Delphi method and AHP. Resources, Conservation and Recycling, 108, 182-197.

[7] Skinner, R., Nelson, R. R., Chin, W. W., \& Land, L. (2015). The Delphi method research strategy in studies of information systems. Communications of the Association for Information Systems, 37(1), 2.

[8] Murray, T. J., Pipino, L. L., \& Gigch, J. P. (1985). A pilot study of fuzzy set modification of Delphi. Human Systems Management, 6-80.

[9] Calabrese, A., Costa, R., Levialdi, N., \& Menichini, T. (2016). A fuzzy Analytic Hierarchy Process method to support materiality assessment in sustainability reporting. Journal of Cleaner Production, 121, 248-264.

[10] Alqarni, F. (2015). Collaborative strategic reading to enhance learners' reading comprehension in English as a Foreign Language. Academic Journal of Interdisciplinary Studies, 4 (1), 161

[11] Jingwei, Z. (2016). Strategies in Improving the Teaching of English Reading by Applying Schema Theory. In Proceedings of The Fifth Northeast Asia International Symposium on Language, Literature and Translation (p. 582).

[12] Gajria, M., \& Jitendra, A. K. (2016). Effective Strategies for Developing Reading Comprehension. In Interventions in Learning Disabilities (pp. 119-137). Springer International Publishing.

[13] Pellicer-Sánchez, A. (2016). Incidental L2 vocabulary acquisition from and while reading. Studies in Second Language Acquisition, 38(01), 97-130.

[14] Quinn, J. M., Wagner, R. K., Petscher, Y., \& Lopez, D. (2015). Developmental relations between vocabulary knowledge and reading comprehension: A latent change score modeling study. Child development, 86(1), 159-175.

[15] McKeown, M. G., \& Curtis, M. E. (2014). The nature of vocabulary acquisition. Psychology Press.

[16] García, J. R., \& Cain, K. (2014). Decoding and reading comprehension: A meta-analysis to identify which reader and assessment characteristics influence the strength of the relationship in English. Review of Educational Research, 84(1), 74-111.

[17] Yusuf, H. O. (2014). Assessment Of The Implementation Of The Reading Component Of The English Language Curriculum For Basic Education In Nigeria. Advances in Language and Literary Studies, 5(2), 96-102.

[18] Gilje, T. M. (2014). Teacher cognition and the teaching of EFL reading in Norwegian upper primary classrooms. Acta Didactica Norge, 8(2), Art-18.

[19] Myrset, A. (2014). A case study of the benefits and challenges of Readers Theatre in a 6th grade Norwegian EFL class (Master's thesis, University of Stavanger, Norway).

[20] Capellini, S. A., Pinto, C. D. A. R., and Cunha, V. L. O. (2015). Reading comprehension intervention program for teachers from 3rd grade'students. Procedia-Social and Behavioral Sciences, 174, 1339-1345. 
[21] Vaish, V. (2016). Student engagement in reading. In Quadrilingual Education in Singapore (pp. 135-151). Springer Singapore.

[22] U. S. Department of Education, National Center for Education Statistics. (2005). The Condition of Education 2005(NCES 2005094). Washington, DC: U. S. Government Printing Office.

[23] Sparks, R. L., Patton, J., \& Murdoch, A. (2014). Early reading success and its relationship to reading achievement and reading volume: Replication of ' 10 years later'. Reading and Writing, 27(1), 189-211.
[24] Young, C., Mohr, K. A., and Rasinski, T. (2015). Reading together: A successful reading fluency intervention. Literacy Research and Instruction, 54(1), 67-81.

[25] Eisavi, V., Homayouni, S., and Karami, J. (2016). Integration of remotely sensed spatial and spectral information for change detection using FAHP. Journal of the Faculty of Forestry Istanbul University| İstanbul Üniversitesi Orman Fakültesi Dergisi, 66(2), 524-538. 